\title{
Prática intersemiótica e intertextuali- dade na crônica Rio, campo minado, de Ferreira Gullar
}

Losana Hada de Oliveira PRADO

\section{Considerações iniciais}

Embora Dominique Maingueneau tenha publicado várias obras desde 1984, ano de Genèses du discours, suas reflexões teóricas iniciadas na década de 1970 e presentes nessa obra, revelam menos o analista do discurso e mais o teórico em discussão acerca dos fenômenos enunciativo-discursivos. Neste capítulo, pretendemos, na perspectiva da Análise do Discurso e com base na obra em questão, refletir acerca da prática discursiva, considerada por Maingueneau (2008) como uma hipótese para a prática intersemiótica, estendendo o universo discursivo para além das margens dos 
objetos linguísticos, ou seja, produções de ordem não linguísticas, que integram domínios semióticos variados (enunciados, quadros, obras musicais etc.).

Diante dessa proposição e da aparente complementaridade entre verbal e não-verbal, a intertextualidade como plano discursivo será uma instância privilegiada na análise da crônica Rio, campo minado, de Ferreira Gullar, bem como a prática intersemiótica será exemplificada na análise da ilustração que acompanha a crônica. Supomos, assim, a independência de objetos de domínios intersemióticos que estão em conformidade a um mesmo sistema de restrições semânticas, princípio formulado por Maingueneau. Soma-se a essa hipótese da prática intersemiótica, dado o caráter interdisciplinar da $\mathrm{AD}$, o conceito de semiótica discursiva (GREIMAS, 2001), que recorremos para estabelecer a dimensão dialógica da discursividade. Segundo Gregolin (1995, p. 14), “embora situadas [Semiótica e Análise do Discurso] em diferentes perspectivas epistemológicas e metodológicas, o que as unifica é o fato de tomarem o seu objeto do ponto de vista linguístico e de procurarem, no texto, o estudo da discursivização".

\section{Uma hipótese e uma instância de enunciação}

Maingueneau, na obra Genèses du discours, formula sete hipóteses para a compreensão do dispositivo enunciativo-discursivo. Para os propósitos de nossa análise, a terceira hipótese que trata da Semântica Global, em particular, a instância da intertextualidade e a sexta hipótese que trata da prática intersemiótica serão aqui associadas.

A intertextualidade, segundo o autor, deixa rastros por meio do intertexto, entendido como o conjunto de fragmentos efetiva- 
mente citados por um discurso, enquanto que a interdiscursividade é constitutiva e, portanto, nem sempre deixa marcas na materialidade linguística. A intertextualidade caracteriza-se pelo tipo de relações definidas como legítimas pelas coerções semânticas, ou seja, pela competência discursiva de um determinado campo, logo, o autor denomina intertextualidade interna a memória discursiva no interior de um dado campo e de intertextualidade externa as relações de um discurso com outros campos, passíveis ou não de serem citados.

Na sexta hipótese, Maingueneau considera a prática discursiva como uma prática intersemiótica. O objetivo dessa reflexão é de estender o universo discursivo para além das margens dos objetos linguísticos, superando formas de abordagem da questão que Maingueneau qualifica de impressionistas ou intuitivas, por intermédio do recurso à noção de prática discursiva, a qual estará em condições de integrar domínios semióticos variados (enunciados, quadros, obras musicais etc.).

O sistema de coerções abrange vários suportes semióticos e, diante de tal reflexão, o autor formula a seguinte proposição:

O pertencimento a uma mesma prática discursiva de objetos de domínios intersemióticos diferentes exprime-se em termos de conformidade a um mesmo sistema de restrições semânticas. Trata-se, evidentemente, de enfrentar um problema de tipologia, descartando ao mesmo tempo a abordagem impressionista, ou, mais amplamente, a intuição de parentescos, de afinidades baseadas em índices heterogêneos, da abordagem "insular" que consiste em isolar cada domínio em seu fechamento. (MAINGUENEAU, 2008, p. 146) 
Assim, Maingueneau redefine a noção de texto, que passará a remeter aos "diversos tipos de produções semióticas que pertencem a uma prática discursiva" (2008, p. 147), e para o termo enunciado, os textos linguísticos. No entanto, o autor comenta que

[...] a coexistência de textos que pertencem a domínios semióticos diferentes não é, entretanto, livre no interior de uma formação discursiva determinada. Não é qualquer domínio que pode figurar com qualquer outro, e essas restrições são função ao mesmo tempo do gênero de práticas discursivas concernidas e do conteúdo próprio de cada uma (MAINGUENEAU, 2008, p. 147).

Dessa forma, o autor propõe que a prática discursiva vai além dos textos verbais e se configura como uma prática intersemiótica, integrando elementos de outros domínios semióticos.

Para exemplificar a hipótese de uma prática intersemiótica, o autor analisa dois quadros ${ }^{34}$ que representariam a discursividade jansenista e a discursividade do humanismo devoto: "Ceia de Emaús”, obra de autoria duvidosa, mas pertencente, sem dúvida, à escola de Philipe de Champaigne, um leigo jansenista, e "Peregrinos de Emaús", quadro de Ticiano que teria servido de inspiração ao primeiro. ${ }^{35}$

34 Imagens extraídas da contracapa da obra Gênese dos Discursos (MAINGUENEAU, 2008).

35 "Ambos os quadros recuperam relato de São Lucas: dois discípulos, após a morte de Jesus, seguiam pelo caminho de Jerusalém a Emaús. Um forasteiro, o próprio Cristo (que, no entanto, não foi reconhecido), aproximou-se e percorreu com eles o trajeto. Chegando a Emaús, convidaram-no a cear. Durante a ceia, quando o forasteiro benzeu o pão, os dois discípulos reconheceram nele o próprio Cristo." (SOUZA-E-SILVA, 2012, p. 118) 


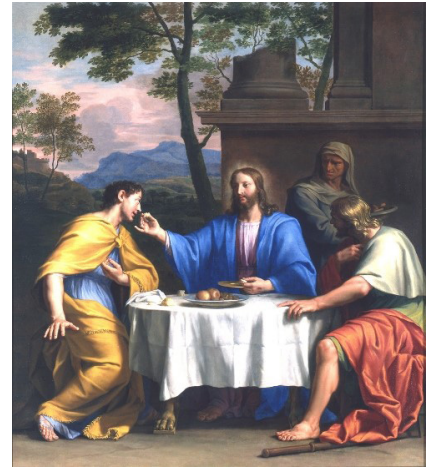

J.-B.Champaigne, "Ceia de Emaús", (1602-1674)

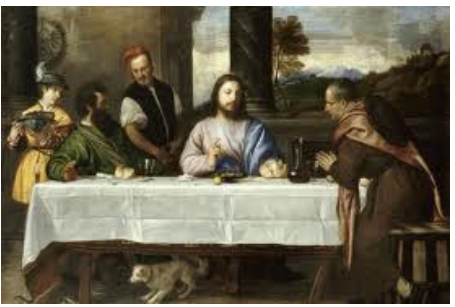

Ticiano, "Os peregrinos de Emaús", (1535-1540)

Maingueneau relata as semelhanças apreendidas entre as obras: ambos os quadros representam uma refeição ao ar livre, com mesa posta, arquitetura que recobre uma metade do fundo, enquanto na outra metade figura uma paisagem; representação da figura de serviçais, presença de Cristo (quase de frente) e de discípulos (de perfil), distribuídos um de cada lado de Cristo.

Para apontar as diferenças, o autor denominou de texto-fonte o quadro de Ticiano (o da pintura do humanismo devoto) e de texto-alvo, o da pintura jansenista. O texto-fonte é um vasto retângulo, diferentemente da pintura jansenista, mais concentrada; os olhares dos personagens respeitam uma hierarquia social e teológica no quadro do humanismo devoto, já na pintura jansenista, olhares se voltam para um único ponto concentrado, representado pela hóstia. Quanto à natureza do desenho em relação ao traçado das linhas de cada obra, na pintura do humanismo devoto, percebe-se a horizontalidade da linha do muro e a verticalidade dos pés da mesa e dos três retângulos da arquitetura do fundo do quadro, contribuindo para manter a ordem hierárquica de três regiões bem distintas (os animais sob a mesa, o universo humano da refeição 
e a esfera celestial na parte superior), representando a coluna em cuja base encontra-se a cabeça de Cristo, o traço de união entre o terrestre e o celestial. No quadro jansenista, em oposição, a circularidade é presente e os personagens encontram-se sentados em torno de uma mesa circular, com objetos circulares (travessa sobre a mesa, pratos, maçãs sobre a mesa) e de um círculo luminoso sobre a cabeça do Cristo.

Outro aspecto de diferença entre as obras está na distribuição de cores e sombras: nuanças de claro/escuro se distribuem por todo o quadro do humanismo devoto, estando a luz predominantemente associada à figura de Cristo na pintura jansenista. $\mathrm{O}$ autor finaliza discorrendo acerca da inscrição social dos dois textos. Enquanto que no texto-fonte (humanismo devoto) vê-se

a vontade de inscrever a cena religiosa no quadro de uma economia doméstica, de definir um espaço familiar de sociabilidade; isso se manifesta ao mesmo tempo pelos detalhes (os objetos sobre a mesa, no chão) e pela atitude das pessoas, uma trazendo um prato, outra vindo conversar com seus clientes. Aqui a refeição guarda todo seu valor de convivência e o Cristo vem inscrever-se nessa sociabilidade para sublimá-la (MAINGUENEAU, 2008, p. 164).

No texto-alvo (jansenismo), há uma diminuição dessa diversidade, uma vez que a pintura só tem lugar como retrato pedagógico da história religiosa, sendo valorizada a busca da "pura espiritualidade". 


\section{A semiótica greimasiana}

Como mencionamos acima, a AD possui, desde sua gênese, um estatuto interdisciplinar. Por isso, visamos a apresentar nessa seção a maneira pela qual a semiótica greimasiana é tomada para a análise do objeto de nosso estudo.

A semiótica estuda a significação, ou seja, entende o texto como objeto de significação e comunicação estabelecida entre destinador e destinatário e, assim, considera o texto em uma articulação entre um plano de conteúdo e um plano de expressão. Enquanto no plano de conteúdo a ideia é analisar o texto no que ele diz e como ele faz para dizer o que diz, no plano de expressão, tem-se a manifestação desse conteúdo em um sistema de significação verbal, não-verbal ou sincrético.

Greimas (1966) propõe uma semiótica que concebe a produção de sentido de um texto como um percurso gerativo, que vai do mais simples e abstrato ao mais complexo e concreto, constituindo três patamares: o fundamental, o narrativo e o discursivo. No nível fundamental, os elementos do conteúdo adquirem sentido por meio das relações estabelecidas entre eles, ou seja, o texto se articula a partir de uma oposição ou diferença mais geral e abstrata na organização mínima de sentido e essa estrutura fundamental é representada por um modelo lógico conhecido como o quadrado semiótico. No nível narrativo, é preciso diferenciar a estrutura sintática da estruturação semântica, uma vez que na sintaxe há uma espécie de descrição da narrativa do texto, como o sujeito se relaciona com o objeto, o que define a instância semio-narrativa da geração do sentido; já na estrutura semântica, os elementos semânticos são selecionados e relacionados com os sujeitos que, por sua vez, podem ser modificados por determinações modais. Quanto ao nível discursivo, trata-se do responsável por concretizar a ins- 
tância geral e abstrata de um enunciador determinado. Em outras palavras, um sujeito da enunciação converte as estruturas narrativas em discurso, mobilizando as categorias sintáticas de pessoa, tempo e espaço.

O que se pretende por meio do percurso gerativo é demonstrar como os sentidos vão se tornando mais complexos e densos no decorrer das etapas: fundamental, narrativa e discursiva. Assim, a semiótica é uma teoria em movimento, herdeira de Saussure, mas que vai além da linguística, estendendo-se para outros domínios, como a da Análise do Discurso e estabelecendo grande poder interdisciplinar.

Para a nossa análise, a articulação se dará no plano do conteúdo com o plano da expressão, uma vez que o conteúdo é conceitual e a expressão é sincrética, assim, crônica (semiótica verbal) e imagem (semiótica visual).

\section{"Rio, campo minado" versus ilustração}

Procederemos à análise da crônica intitulada Rio, campo minado, de Ferreira Gullar, publicada em 11 de julho de 2010, no jornal Folha de S. Paulo:

UM BUEIRO explodiu em plena avenida Nossa Senhora de Copacabana, a umas poucas esquinas de minha casa, e lançou pelos ares um casal de norte-americanos que tinha vindo à cidade maravilhosa a serviço. Estão os dois num hospital, ela com $85 \%$ do corpo queimado.

O bueiro que explodiu é da Light, a empresa que fornece energia elétrica à cidade. Sei, por uma conhecida que é 
médica e atende em hospital público, que esse não foi o primeiro bueiro a explodir, outras pessoas morreram em suas mãos, queimadas por explosões semelhantes, ocorridas na zona norte do Rio.

Só que, como foi na zona norte e as vítimas eram gente humilde, nada se soube. Parece que este é o sétimo bueiro que explode.

A verdade é que nós, moradores do Rio, vivemos em cima de um campo minado. Você, eu, seu filho, qualquer um de nós poderá amanhã voar pelos ares ao passar sobre um bueiro da Light. Como sair desta? Se cabe ao governo fiscalizar o desempenho das empresas para impedir que ocorram coisas assim, por que ocorrem? As empresas subornam os responsáveis pela fiscalização?

A impressão é de que quem deveria defender nossos direitos passou para o lado dos que os solapam. Se empresas e Estado estão unidos contra nós, talvez a saída seja tomarmos as rédeas e fazermos como no caso da Ficha Limpa. Se os que estão politicamente organizados passaram para o outro lado, cabe ao povo desorganizado tomar de volta a autoridade delegada a eles.

Ao prefeito do Rio:

Excelentíssimo prefeito Eduardo Paes, desculpe-me se me dirijo publicamente ao senhor para tratar de assunto tão miúdo. É que lhe escrevi uma carta a respeito e não obtive resposta, mas agora que decidiu agir contra os buracos de rua, meu assunto se torna oportuno, pois, 
muito embora miúdo, tem enorme importância para as pessoas que residem à rua Sebastião Drumond, no bairro Anchieta.

Lá mora Maria das Dores da Costa, que trabalha em minha casa e tem um filho inválido, de dez anos, que não fala nem fica em pé. Para levá-lo ao terapeuta, vale-se de uma cadeira de rodas, em que o conduz até a esquina onde passam ônibus e táxis. Na rua dela, não passa nada disso, sabe por quê? Porque a rua é uma vala só, de uma esquina a outra. A bem dizer, não é rua, é um buraco de muitos metros de comprimento. Esse buraco, senhor prefeito, foi se aprofundando e alargando, a cada ano, a tal ponto que já toma quase toda a largura da rua.

Significa que os moradores dispõem atualmente de apenas alguns palmos de chão, ao saírem de casa e irem ao trabalho ou às compras. E cada dia que passa, como o buraco aumenta, há menos chão para pisar, de modo que, em breve, não poderão mais sair de suas casas, porque o buraco terá tomado conta da rua toda. O buraco é grande, mas a rua é relativamente pequena, senhor prefeito. Será que o senhor poderia, num de seus poucos momentos disponíveis, socorrer os moradores da rua Sebastião Drumond, antes que o buraco engula também as próprias casas onde moram?

Peço que releve a ousadia, mas é que, por minha conta, sem ter sido eleito por ninguém, atribuí-me a obrigação de falar por essas pessoas cuja voz ninguém ouve. Espero que desta vez o senhor nos ouça. 
* Esta Copa começou chata, mas depois se tornou instigante. No jogo Brasil versus Holanda, tivemos a performance de Felipe Melo, que sozinho fez tudo: deu o passe para o gol de Robinho, fez o gol da Holanda e ainda pisou num adversário para ser expulso e facilitar nossa derrota.

Mas inacreditável mesmo foi o jogo de Paraguai com Espanha, quando um jogador espanhol agarrou pelo braço um adversário até jogá-lo no chão e provocar um pênalti. Vibrei, mas o paraguaio chutou nas mãos do goleiro. E não é que, em seguida, o Paraguai cede também um pênalti ao adversário? Xabi Alonso bateu e fez, mas o árbitro anulou porque houve invasão da área.

Xabi bateu de novo, mas aí o goleiro Villar defendeu. Não dava para acreditar. Foi então que a Espanha invadiu a área paraguaia, Pedro chutou livre, mas, caprichosamente, a bola acertou a trave de novo; mas sobrou para Villa, que também chutou, e ela outra vez bateu numa das traves, depois na outra trave e finalmente entrou! Comecei a rir, parecia um filme dos Trapalhões.

** Lula aprovou a atuação de Dunga. Claro! Yabadabadoo!

"Rio, campo minado" é um título que aciona a ideia de guerra por meio do vocabulário "minado", dispositivo usado em campo de guerra para flagrar e matar o inimigo. Entretanto, associado à cidade do Rio de Janeiro, o termo ganha novo sentido, mas não diferente da ideia de guerra, uma vez que é sabido que a cidade 
enfrenta sérios problemas de violência urbana. $\mathrm{O}$ enunciador faz uma denúncia: um bueiro explode na avenida Nossa Senhora de Copacabana, ferindo um casal de norte-americanos. Se não fosse o trecho “... a umas poucas esquinas de minha casa..., poderíamos configurar o primeiro parágrafo como o lide de uma notícia. No entanto, o discurso construído em primeira pessoa produz efeito de sentido de aproximação do sujeito enunciador com o que se diz em uma relação dialógica. É feito reflexões sobre o ocorrido.

\section{Recorte 1}

Um bueiro explodiu em plena avenida Nossa Senhora de Copacabana, a umas poucas esquinas de minha casa, e lançou pelos ares um casal de norte-americanos que tinha vindo à cidade maravilhosa a serviço. Estão os dois num hospital, ela com $85 \%$ do corpo queimado.

O bueiro que explodiu é da Light, a empresa que fornece energia elétrica à cidade. Sei, por uma conhecida que é médica e atende em hospital público, que esse não foi o primeiro bueiro a explodir, outras pessoas morreram em suas mãos, queimadas por explosões semelhantes, ocorridas na zona norte do Rio.

Nesse recorte, o enunciador continua discorrendo sobre o tema do bueiro que era da Light e que explodiu e afirma não ter sido o primeiro, mencionando saber, por intermédio de uma conhecida médica, que outros bueiros já haviam explodido e que pessoas haviam morrido queimadas. Ainda em relação ao vocabulário, palavras e expressões como "explodiu", "lançou pelos ares", "voar pelos ares", "campo minado" confirmam o título da crônica 
e a ideia de guerra, uma vez que se trata do mesmo princípio de explosão para atingir pessoas. A ironia é acionada para criticar os meios de comunicação que não divulgam fatos ocorridos com pessoas pobres, vítimas dos bueiros, dos campos minados, e que nada é feito para protegê-las porque é "gente humilde" e moradores da zona norte do Rio.

Recorte 2

Só que, como foi na zona norte $e$ as vítimas eram gente humilde, nada se soube. Parece que este é o sétimo bueiro que explode. A verdade é que nós, moradores do Rio, vivemos em cima de um campo minado. Você, eu, seu filho, qualquer um de nós poderá amanhã voar pelos ares ao passar sobre um bueiro da Light. Como sair desta? Se cabe ao governo fiscalizar o desempenho das empresas para impedir que ocorram coisas assim, por que ocorrem? As empresas subornam os responsáveis pela fiscalização?

O uso do demonstrativo "este", no recorte 2, indica que o fato ocorrido é presente, ou seja, apesar de se tratar do "sétimo bueiro que explode", o enunciador se refere ao último e, por isso, um acontecimento do "dia a dia", quase banal. O ocorrido ontem será escrito e publicado hoje, característica desse tipo de texto, que aproxima os acontecimentos que lhe servem de tema. $\mathrm{O}$ enunciador, ao mesmo tempo em que "denuncia" o descaso da prefeitura em relação aos bueiros da cidade do Rio de Janeiro, opina acerca de evento esportivo, Copa do Mundo. Nesse contexto imediatista diante de tantos fatos cotidianos, o enunciador também quer "fa- 
lar" de tudo o que acontece e que lhe parece significativo. Podemos afirmar que o texto não visa à erudição, mas à denúncia que gera polêmica. Trata-se de um texto de fácil compreensão, outra característica desse gênero.

A partir do quarto parágrafo, ainda no recorte 2, o enunciador estabelece um diálogo, comentando e articulando um discurso de protesto "A verdade é que nós, moradores do Rio, vivemos em cima de um campo minado". O enunciador procura provocar o co-enunciador diretamente, por meio do dêitico de pessoa, recurso muito utilizado para persuadir e conseguir a adesão, dessa forma, fazê-lo se sentir parte do discurso proferido. O enunciador chama o co-enunciador à reflexão dos fatos "Você, eu, seu filho, qualquer um de nós poderá amanhã voar pelos ares ao passar sobre um bueiro da Light." Em seguida, faz três perguntas retóricas: "Como sair desta? Se cabe ao governo fiscalizar o desempenho das empresas para impedir que ocorram coisas assim, por que ocorrem? As empresas subornam os responsáveis pela fiscalização?”

\section{Recorte 3}

A impressão é de que quem deveria defender nossos direitos passou para o lado dos que os solapam. Se empresas e Estado estão unidos contra nós, talvez a saída seja tomarmos as rédeas e fazermos como no caso da Ficha Limpa. Se os que estão politicamente organizados passaram para o outro lado, cabe ao povo desorganizado tomar de volta a autoridade delegada a eles. 
O recorte acima mostra a resposta hipotética: “... talvez a saída seja tomarmos as rédeas e fazermos como no caso da Ficha Limpa".

Uma das características do dialogismo é a utilização de perguntas e, as feitas pelo enunciador, manifestam um pedido de esclarecimento e, nesse momento, há uma articulação e proposta de respostas. Vemos também que, na elaboração da resposta, fazse alusão à Lei Ficha Limpa ${ }^{36}$ e o co-enunciador precisaria da ativação do conhecimento enciclopédico para relacionar os fatos apresentados e retomar na memória de curto prazo o que é a referida lei.

\section{Recorte 4}

Ao prefeito do Rio:

Excelentíssimo prefeito Eduardo Paes, desculpe-me se me dirijo publicamente ao senhor para tratar de assunto tão miúdo. É que lhe escrevi uma carta a respeito e não obtive resposta, mas agora que decidiu agir contra os buracos de rua, meu assunto se torna oportuno, pois, muito embora miúdo, tem enorme importância para as pessoas que residem à rua Sebastião Drumond, no bairro Anchieta.

Lá mora Maria das Dores da Costa, que trabalha em minha casa e tem um filho inválido, de dez anos, que

36 Lei Complementar que estabelece casos de inelegibilidade, prazos de cessação e determina outras providências, para incluir hipóteses de inelegibilidade que visam a proteger a probidade administrativa e a moralidade no exercício do mandato. Disponível em: http://www.planalto.gov.br/ccivil_03/leis/LCP/Lcp135. htm. Acesso em: 16/04/2018. 
não fala nem fica em pé. Para levá-lo ao terapeuta vale-se de uma cadeira de rodas, em que o conduz até a esquina onde passam ônibus e táxis. Na rua dela, não passa nada disso, sabe por quê? Porque a rua é uma vala só, de uma esquina a outra. A bem dizer, não é rua, é um buraco de muitos metros de comprimento. Esse buraco, senhor prefeito, foi se aprofundando e alargando, a cada ano, a tal ponto que já toma quase toda a largura da rua.

Significa que os moradores dispõem atualmente de apenas alguns palmos de chão, ao saírem de casa e irem ao trabalho ou às compras. E cada dia que passa, como o buraco aumenta, há menos chão para pisar, de modo que, em breve, não poderão mais sair de suas casas, porque o buraco terá tomado conta da rua toda. O buraco é grande, mas a rua é relativamente pequena, senhor prefeito. Será que o senhor poderia, num de seus poucos momentos disponiveis, socorrer os moradores da rua Sebastião Drumond, antes que o buraco engula também as próprias casas onde moram?

Peço que releve a ousadia, mas é que, por minha conta, sem ter sido eleito por ninguém, atribuí-me a obrigação de falar por essas pessoas cuja voz ninguém ouve. Espero que desta vez o senhor nos ouça.

É notória, em crônicas jornalísticas, a presença de um gênero que exerce a função de outro com o objetivo de produzir determinados efeitos de sentido. É o que as autoras Koch, Bentes e Cavalcante (2007) chamam de intergenericidade ou intertextualidade 
(inter)genérica e que Marcuschi (2002) denomina configuração híbrida. No entanto, essa "contaminação" não gera dificuldade interpretativa, já que predomina a função sobre a forma na determinação do gênero. Esse recurso é usado pelo enunciador quando o gênero carta (que compreende a seguinte forma: data, saudação, corpo, despedida e assinatura) é inserido no texto.

As características da carta de enunciador não seguem exatamente a estrutura determinada desse gênero, justamente por ela fazer parte de uma crônica. Não há, por exemplo, data, uma vez que esta se encontra impressa pelo próprio jornal. A despedida não é cordial, mas um período final que expressa o desejo em ser atendido e, quanto à assinatura, ela também se encontra logo abaixo do título da crônica, então, não sendo necessário mencionar que se trata de uma carta do escritor Ferreira Gullar.

O enunciador estabelece uma crítica social bastante acentuada e dialoga com o co-enunciador procurando persuadi-lo a compartilhar de seu ponto de vista e, por meio do gênero carta e usando da ironia, dirige-se ao prefeito Eduardo Paes para tratar de um problema não muito diferente do dos bueiros: agora são os buracos. A ironia é considerada um caso típico de discurso bivocal, uma vez que nesse discurso a palavra tem duplo sentido: volta-se para o objeto do discurso como palavra comum e para outro discurso. De acordo com Bakhtin (2003, p. 284), "a segunda voz, uma vez instalada no discurso do outro, entra em hostilidade com o seu agente primitivo e o obriga a servir a fins diametralmente opostos. O seu discurso se converte em palco de luta entre duas vozes."

Sabendo que há diferentes tipos de carta, como a pessoal, a comercial, a de reclamação, a de solicitação etc., notamos que a carta do enunciador é de reclamação. Nela é feito um pedido ao prefeito de maneira pública "dirijo-me publicamente ao senhor", uma vez 
que a carta já é a segunda, a primeira não foi respondida. O enunciador trata do assunto dos buracos na Rua Sebastião Drumond, onde mora sua empregada Maria das Dores da Costa que tem dificuldade para levar o filho inválido ao terapeuta, pois na rua em que mora não passa nem ônibus nem táxi por causa dos buracos. Usando da ironia, o enunciador pede ao prefeito que "num de seus poucos momentos disponíveis" solucione o problema dos buracos e aproveita para se desculpar por, "sem ter sido eleito por ninguém", ver-se como porta-voz de pessoas que ninguém ouve. A ironia está no fato do enunciador não ter sido eleito e se manifestar, e, por sua vez, o prefeito, eleito pelo povo, nada fazer em relação a um problema de sua competência. A ironia, nesse caso, é "autorizada" porque o interlocutor, no caso o prefeito, não estabelece relação de confiança e respeito mútuo, logo, a lei da sinceridade não está sendo cumprida, o que permite o uso da ironia para demonstrar a mesma insinceridade.

A carta encaminhada ao prefeito Eduardo Paes, por meio da crônica, é, segundo o enunciador, respondida, e o problema do buraco na rua Sebastião Drumond, resolvido. O enunciador retoma esse tema na crônica intitulada Oi tortura!, ${ }^{37}$ publicada no dia 10 de abril de 2011. O enunciador menciona a resposta do prefeito e prossegue com a temática das denúncias, agora contra a $\mathrm{O} i$, companhia telefônica do Rio de Janeiro. Temos, nesse momento, além da intertextualidade, a intratextualidade, ou seja, a relação dialógica que o enunciador estabelece consigo.

A crônica em análise pode ser dividida em três partes: a primeira refere-se à temática dos bueiros que explodem na cidade do Rio de Janeiro, a segunda é sobre a Copa do mundo e a terceira consiste em apenas uma nota a respeito do então presidente da república, Luís Inácio Lula da Silva.

37 Crônica Oi tortura!, de Ferreira Gullar, publicada no dia 10 de abril de 2011 


\section{Recorte 5}

Esta Copa começou chata, mas depois se tornou instigante. No jogo Brasil versus Holanda, tivemos a performance de Felipe Melo, que sozinho fez tudo: deu o passe para o gol de Robinho, fez o gol da Holanda e ainda pisou num adversário para ser expulso e facilitar nossa derrota.

Mas inacreditável mesmo foi o jogo de Paraguai com Espanha, quando um jogador espanhol agarrou pelo braço um adversário até jogá-lo no chão e provocar um pênalti. Vibrei, mas o paraguaio chutou nas mãos do goleiro.

O tema futebol é tratado com bastante ironia, o enunciador diz que a Copa começou chata e que depois se tornou instigante. A afirmação reside no fato de o Brasil, na partida contra a Holanda, ter perdido, mas, ter tido a performance do jogador Felipe Melo que, depois de ter feito tudo, acabou sendo expulso. A ironia e o tom jocoso estão na comparação feita acerca da partida entre Paraguai e Espanha, em que os lances pareciam um filme antigo dos anos 80 dos Trapalhões, programa televisivo de humor exibido na Rede Globo. A finalização, terceira parte da crônica, é uma referência de que o presidente Lula tivesse aprovado a atuação do técnico Dunga.

A seguir, isolamos a ilustração de seu componente verbal, no caso, a crônica em análise. 


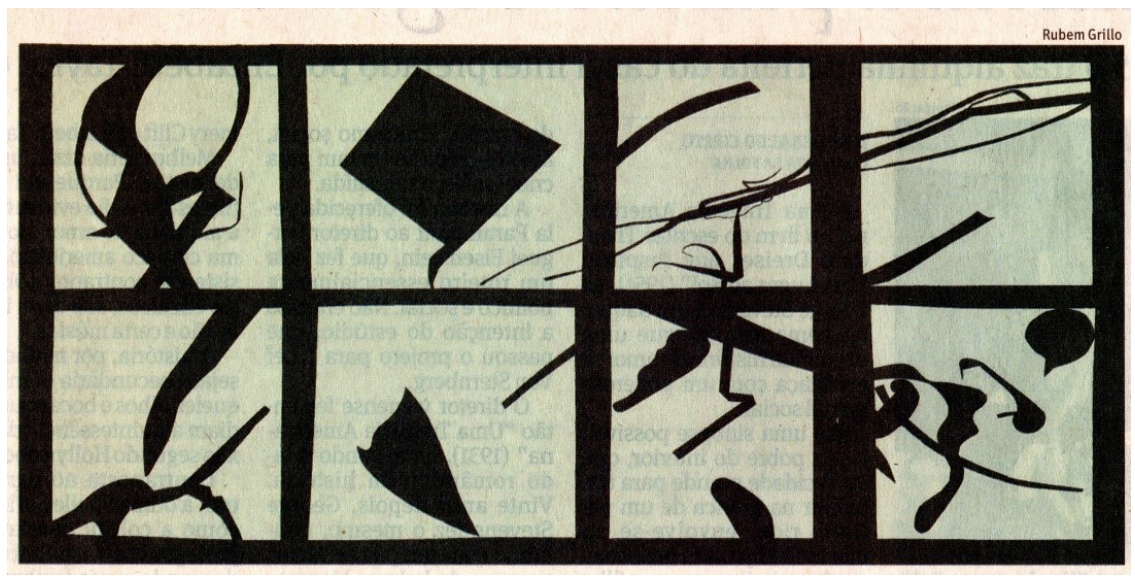

(Ilustração de Rubem Grillo)

A semiótica possui facetas que ajudam a interpretar a imagem e entender como ela transmite mensagens, no entanto, compreendemos que é o repertório visual e cultural de cada indivíduo que permite diferentes interpretações de uma mesma imagem, além do fato de a materialidade semiótica manter relação intrínseca com as condições sócio-históricas e culturais de dada sociedade. do momento sociocultural de uma sociedade.

A ilustração acima, de autoria de Rubem Grillo ${ }^{38}$, mostra uma abstração, uma assimetria dos quadrados e, ao fundo, imagens sem

38 Rubem Campos Grillo (Pouso Alegre, MG, 1946). Gravador, ilustrador, professor, curador. Em 1963, transfere-se para Itaguaí, Rio de Janeiro, e, aos 23 anos, conclui o curso de agronomia pela Universidade Federal Rural do Rio de Janeiro - UFRRJ. No início da década de 1970, ilustra jornais como Opinião, Movimento, Versus, Pasquim, Jornal do Brasil. Na Folha de S. Paulo, é ilustrador da coluna de Ferreira Gullar, aos domingos na Ilustrada. Disponível em: http:// eudyrj.wordpress.com/rubem-grillo/ Acesso em: 04/04/2018. 
formas definidas. A cor preta é predominante e coerente com a questão dos bueiros e das explosões relatadas pelo autor. Influenciados pela leitura do verbal, é possível apreender que se trata de um lugar devastado, talvez um campo minado. Os destroços depois de uma explosão transformaram-se em imagens que não podem ser identificadas e a ilustração é coerente com o verbal, uma vez que o texto aborda a questão dos bueiros que explodiram no Rio de Janeiro.

Retomando o princípio de Maingueneau (2008) acerca da prática discursiva que vai além dos textos verbais, configurando-se como uma prática intersemiótica, os efeitos de sentido que orientam os percursos do olhar sobre os objetos, no nosso caso em análise a ilustração isolada do texto verbal, constatamos que as categorias de expressão geram modos de relação entre o enunciador e o co-enunciador, estabelecendo pontos de vista distintos. A ilustração é vista em primeiro plano e a construção de sentido difere daquela construída por meio do plano de conteúdo.

Enquanto o texto-fonte no exemplo de Maingueneau (1997) é o quadro de Ticiano (o da pintura do humanismo devoto), na nossa análise é a crônica (texto verbal) e o texto-alvo (pintura jansenista), a ilustração que acompanha o texto.

No plano da expressão, é possível opor guerra vs. paz, o bueiro que explode e que contrasta com a cor cinza e o imaginário das cores claras de uma cidade como o Rio de Janeiro. Segundo Pietroforte (2017), a semiótica verbal pertence também à semiótica plástica, descrita pela cor e pela forma. Assim, o texto-fonte (crônica) estabelece vínculo com o texto-alvo (ilustração), que integram e também imprimem estilo individual dos enunciadores. 


\section{Considerações finais}

Na crônica "Rio, campo minado", de Ferreira Gullar, o enunciador faz denúncias sociais, ou seja, informa acerca de um bueiro que explodiu em plena Copacabana e um buraco na rua onde mora sua empregada. O enunciador se vê como porta-voz do cidadão comum que não é ouvido pelas autoridades, e o gênero crônica, que prima muitas vezes pelo descompromisso com a informação, nesse caso, passa a ser o elo entre leitor-cidadão e autoridade governamental. Isso significa que todo o processo comunicativo passa necessariamente por uma relação interdependente e interindividual: o discurso está necessariamente ligado a outros discursos. Por isso, Bakhtin (2006) concebe a linguagem como um sistema coletivo determinado por um diálogo cumulativo entre os diversos "eus" e os diversos "outros".

Concordamos com Maingueneau (2008) ao afirmar que não há como privilegiar "planos", regras para o funcionamento semântico, e que é o olhar do analista que seleciona o campo de seu interesse para comprovar sua análise e, assim, ampliar as possibilidades de abordagem de um mesmo corpus.

Em relação à ilustração que acompanha a crônica, o objetivo da análise foi de um olhar de ordem não linguística, porém inserido no plano da estrutura semiótica que, segundo Maingueneau, não pode restringir o universo discursivo aos objetos linguísticos e que os suportes intersemióticos são dependentes uns dos outros.

Reconhecemos a necessidade de aprofundamento e apropriação dessa prática intersemiótica aplicada às análises que contemplam o verbal e o não-verbal (sincrético), buscando as relações estabelecidas entre os dois sistemas. No que concerne à imagem, a palavra pode ter duas funções: de ancoragem ou de etapa. A esse respeito, Barthes (1984, p. 32) afirma que "toda imagem é polis- 
sêmica, implicando, subjacente aos seus significantes, uma 'cadeia flutuante' de significados, dos quais o leitor pode escolher uns e ignorar outros".

É pensando nesse leitor, no olhar desse leitor, nesse leitor analista ou não de um discurso, que apontamos possibilidades leitoras e/ou análises que deslocam esse olhar para outras direções (im) possíveis.

\section{Referências}

BAKHTIN, Mikhail. Estética da criação verbal. Trad. Paulo Bezerra. $4^{\text {a }}$ ed. São Paulo: Martins Fontes, 2003.

. Marxismo e Filosofia da Linguagem. Trad. Michel Lahud e Yara Frateschi Vieira. 12a ed. São Paulo: Hucitec, 2006.

BARTHES, Roland. O óbvio e o obtuso. Lisboa: Edições 70, 1984.

GREGOLIN, Maria do Rosário de Fátima V. No diagrama da AD Brasileira: heterotopias de Michel Foucault, 1995.

GREIMAS, Algirdas J. Sémantique structural. Paris: Larousse, 1966.

GREIMAS, Algirdas. J. e COURTĖS, Joseph. Sémiotique: Dictionnaire raisonné de la théorie du langue. Paris, Hachette. 1979.

KOCH, Ingedore G. Villaça; BENTES, Anna Christina e CAVALCANTE, Mônica Magalhães. Intertextualidade: diálogos possíveis. São Paulo: Contexto, 2007.

MAINGUENEAU, Dominique. Gênese dos Discursos. Tradução Sírio Possenti. São Paulo: Parábola, 2008.

MARCUSCHI, Luiz Antônio. Produção Textual Análise de Gêneros e Compreensão. São Paulo: Parábola, 2002.

PIETROFORTE, Antônio Vicente. Análise do Texto Visual. São Paulo: Contexto, 2017. 